\title{
Mediterranean Diet beyond the Mediterranean Basin: Chronic Disease Prevention and Treatment
}

\author{
Guadalupe Echeverría, Catalina Dussaillant, \\ Emma McGee, Inés Urquiaga, Nicolás Velasco and \\ Attilio Rigotti
}

Additional information is available at the end of the chapter

http://dx.doi.org/10.5772/intechopen.68937

\begin{abstract}
The Mediterranean diet (MedDiet) is considered one of the healthiest dietary patterns. Current scientific evidence supports that this dietary pattern is associated with lower prevalence and incidence of a number of chronic diseases, such as cardiovascular disease, diabetes, cancer, and age-related cognitive decline as well as reduced overall mortality. The Mediterranean diet includes a wide variety of foods that are eaten in moderation and enjoyed in a positive social environment. It is characterized by a high intake of fruits and vegetables, whole grains, legumes, nuts, fish and seafood, white meats, olive oil, herbs, and spices paired with moderate consumption of fermented dairy products and wine and low intake of red meat, butter, and sugar. The generic term "Mediterranean diet" was coined in the Seven Countries Study led by Ancel Keys in the 1950s. Yet, in spite of its name, this dietary pattern and its benefits are not confined exclusively to the Mediterranean Basin. Among other world regions, Central Chile exhibits climate, agriculture, and culinary traditions similar to various Mediterranean countries. It is therefore essential to increase awareness about the Mediterranean-like richness of both produce and culinary culture beyond the Mediterranean Basin. Active promotion of this dietary pattern may offer health benefits and improve the quality of life in many populations worldwide.
\end{abstract}

Keywords: Mediterranean diet, human health, chronic disease prevention, Chile, lifestyle

\section{Introduction}

Noncommunicable diseases (NCDs), also known as chronic diseases, are the leading cause of death worldwide, representing an increasing healthcare burden and a growing concern 
for national and international public health agencies [1]. Currently, most NCD deaths occur in low- and middle-income countries rather than in developed regions. The rise of NCDsobesity, diabetes, cardiovascular diseases, chronic lung disease, and cancer-has been driven by predisposing lifestyle-related risk factors, including physical inactivity, unhealthy diet, and tobacco use. Notably, diets rich in saturated fats, polyunsaturated omega- 6 fatty acids, trans-fatty acids, and refined carbohydrates-along with a low supply of antioxidants and fiber-are harmful to human health [2].

At the population level, there is a consensus that lifestyle improvement is the most cost-effective approach that can be used in preventive and therapeutic programs aimed at stopping the ongoing NCD epidemic and avoiding excessive medicalization of NCD management through pharmacological or surgical interventions. Among these lifestyle improvement measures, promotion of a healthy diet plays a critical role. Indeed, healthy dietary patterns can modify the population risk profile for chronic diseases, and the association between high-quality diet, better health, and less disease is widely accepted [3].

A large amount of scientific evidence supports the claim that the Mediterranean diet (MedDiet) is beneficial for human health and disease prevention [4, 5]. However, this dietary pattern and its benefits are not exclusively confined to the Mediterranean Basin. Among others, Central Chile is one region that exhibits climate, agriculture, and culinary traditions similar to various Mediterranean countries. In this book chapter, we (1) review the origin of the MedDiet concept; (2) analyze evidence supporting its positive impact on human health; (3) assess geographical, ecological, and agricultural evidence indicating that Central Chile may be considered a Mediterranean-like region; (4) discuss traditional Chilean cuisine as related to Mediterranean diets; and (5) analyze pilot studies on dietary Mediterranization and its impact on biomarkers, risk factors, and disease conditions in Chilean adults.

\section{The Mediterranean diet}

The MedDiet is currently considered one of the healthiest dietary patterns in the world $[4,5]$. MedDiet was born and popularized as a concept in the middle of the twentieth century as a consequence of major findings reported in the Seven Countries Study, led by Ancel Keys and colleagues in the 1950s, which compared the relationship between dietary habits and cardiovascular disease outcomes in 16 different cohorts from the USA, Japan, Finland, the Netherlands, former Yugoslavia, Italy, and Greece [6]. Comparative follow-up from 5 to 25 years confirmed a lower mortality from coronary heart disease and showed decreased overall mortality and longer life expectancy in association with dietary patterns found in Crete and Corfu (Greece), Montegiorgio (Italy), and Dalmatia (Croatia, formerly in Yugoslavia), despite the consumption of a high-fat diet due to significant intake of olive oil [7].

It is important to emphasize that there is no single MedDiet pattern. In fact, the Mediterranean Basin includes several countries that differ in their dietary intake. However, an overall 
Mediterranean dietary pattern can be defined in Spain, Southern France, Italy, and Greeceand even in North Africa and the Middle East - where diets are characterized by high intake of fruits and vegetables, whole grains, legumes, nuts, fish and seafood, white meats, olive oil, herbs, and spices; moderate consumption of fermented dairy products and wine; and low intake of red meat, whole milk, and butter as well as sugar and sugary foods. From a nutritional perspective, the MedDiet is low in saturated fats, refined carbohydrates, and terrestrial animal protein, is high in antioxidants, fiber, and monounsaturated fats; and exhibits an adequate omega-6/omega-3 fatty acid balance. As indicated by this description, the MedDiet includes a wide variety of foods that are combined in a specific consumption frequency (Table 1) to prepare appealing and tasty meals rather than restricting specific foods or nutrients.

The MedDiet includes a wide range of foods rich in bioactive components, which are responsible for the dietary pattern's beneficial health effects [8-12]. Among these components, the most important are antioxidants, fiber, and phytosterols from vegetables, fruits, virgin olive oil, and wine; monounsaturated fatty acids from olive oil; omega-3 fatty acids mainly from marine products and nuts; and probiotics provided by fermented foods such as cheese, yogurt, and others. Through multiple concurrent and synergistic mechanisms, the MedDiet generates diverse and favorable physiological and metabolic changes (e.g., improvement in antioxidant defense, lipid profile, blood pressure, inflammation,

\begin{tabular}{|c|c|}
\hline Food group & Consumption frequency \\
\hline Vegetables & $\begin{array}{l}\text { Daily, in abundant amount, three or more servings per } \\
\text { day, raw or cooked }\end{array}$ \\
\hline Fruits & $\begin{array}{l}\text { Daily, in abundant amount, two or more servings per } \\
\text { day }\end{array}$ \\
\hline Olive oil & Daily, three to six tablespoons per day, as main fat source \\
\hline Cereal grains, mainly bread and pastries & Daily, three to four times a day, in moderate amount \\
\hline Legumes & At least three times a week \\
\hline Nuts & At least three times a week \\
\hline Dairy products, mainly fermented yogurts and cheeses & Daily, two to four servings per day \\
\hline Eggs & One to four units per week \\
\hline Fish and seafood & Two to four times per week \\
\hline Poultry & Two to four times per week \\
\hline Red and processed meats & One time per week or less \\
\hline Wine & $\begin{array}{l}\text { Daily, moderate consumption (one glass a day for } \\
\text { women and two glasses a day for men), on a regular } \\
\text { basis, mainly with meals }\end{array}$ \\
\hline Spices and condiments & Daily, varied use in the preparation of meals \\
\hline
\end{tabular}

Table 1. Food components and consumption frequencies in a Mediterranean diet. 
and coagulation together with modulation of gene expression) [8, 13-16] that ultimately improve health, lower the risk of chronic diseases, promote longevity, and enhance quality of life.

However, the MedDiet includes more than just food. The term diet is being derived from the Greek word diaita which has the meaning of the way of life/lifestyle. The MedDiet constitutes a set of skills, knowledge, and traditions stretching from the land to the table, including farming, fishing, conservation and processing, preparation, and-finally-consumption of food. Furthermore, this lifestyle also promotes social interaction, since familial and communal meals are the cornerstone of social customs and festive events. As a result, UNESCO recognized the MedDiet as Intangible Cultural Heritage in 2010 [17].

\section{Mediterranean diet and human health/disease prevention}

Increasing observational and interventional scientific evidence illustrates that MedDiet is beneficial for human health and disease prevention, leading to considerable interest in its application as a tool for attenuating the global impact of NCDs.

\subsection{Observational studies}

Several cross-sectional and prospective cohort studies have associated the MedDiet with lower prevalence and incidence of a number of chronic conditions, such as metabolic syndrome (MS), diabetes, coronary artery disease, cancer, and neurodegenerative diseases, as well as reductions in overall mortality.

MS is a set of clinical conditions that increases the risk of cardiovascular disease and other health complications. A large meta-analysis concluded that adherence to a Mediterraneantype diet is associated with a lower risk of MS, with a protective effect on all its components (hyperglycemia, high triglycerides, low HDL cholesterol, high blood pressure, and abdominal obesity) [18]. A high MedDiet score has also been correlated with a lower incidence of diabetes as well as improved metabolic control and decreased total mortality in diabetic patients [19-21]. Furthermore, meta-analysis of several large prospective cohort studies indicates that increased adherence to a MedDiet is significantly associated with reduced cardiovascular disease incidence and mortality $[22,23]$.

In regards to cancer, meta-analysis based on cumulative information showed that high adherence to MedDiet consumption was associated with lower incidence and mortality from malignant neoplasia [24]. More specifically, the lower overall risk of cancer found in Mediterranean countries is mainly due to a lower incidence of colon, endometrial, breast, and prostatic cancer [25].

Given the ongoing aging of the world population, the prevalence of neurodegenerative diseases has dramatically increased. In several observational studies, the MedDiet pattern has been linked with attenuation of mild cognitive impairment associated with aging as well as reduced incidence of Alzheimer's and Parkinson's diseases [26]. All these findings have been confirmed by meta-analytical approaches $[22,24]$. 


\subsection{Interventional studies}

To date, several randomized clinical trials have shown that Mediterranean-type diets are more effective than other diets in inducing clinically favorable long-term changes in cardiovascular risk factors and inflammatory markers [27]. This evidence strongly suggests that a MedDiet may have positive effects on clinical outcomes related to NCDs. Indeed, prospective interventional clinical studies - particularly the PREDIMED (Prevention with Mediterranean Diet) initiative in Spain [28] - have established that following a Mediterranean-type diet lowers the incidence of cardiovascular disease and attenuates the risk of diabetes, breast cancer, and age-related cognitive decline.

The first prospective intervention trial assessing MedDiet's impact on clinical outcomes was the Lyon Diet Heart Study (1988-1992). In this study, patients with a previous myocardial infarction (MI) were randomized to either $\alpha$-linolenic fatty acid-enriched MedDiet or a prudent control diet [29]. The major finding was that, after a follow-up period of 27 months, subjects following the MedDiet had a significantly reduced recurrence of MI and other cardiac events as well as decreased overall mortality. An extended follow-up (46 months) confirmed these findings indicating the long-term effectiveness of the MedDiet in reducing coronary clinical events in secondary prevention [30].

More recently, the multicenter PREDIMED study was conducted in Spain, between the years 2003 and 2011. This study included men and women with high risk for NCDs but without previous cardiovascular events. Participants were randomized to MedDiet supplemented with extra virgin olive oil, MedDiet supplemented with nuts, or a low fat diet (control group) [28]. Both types of MedDiet intervention groups showed benefits on different cardiovascular risk factors such as dyslipidemia, insulin resistance, inflammation, and oxidation [28]. They also had a favorable effect on MS, improving its components and decreasing its overall prevalence via reversion with respect to baseline [31, 32]. After 4.8 years of follow-up, participants assigned to MedDiets-supplemented with either olive oil or nuts-exhibited a 30\% reduction in cardiovascular event risk, mainly due to stroke, compared to the control group [33]. Additional analyses of this trial have revealed a significantly lower incidence of newly diagnosed cases of diabetes among nondiabetic subjects who followed a MedDiet as compared to the control group [34]. Finally, the PREDIMED study also demonstrated that the MedDiet reduces cognitive impairment associated with aging [35] as well as breast cancer incidence [36]. The PREDIMED study therefore provides strong scientific evidence regarding the beneficial role of MedDiet in the prevention of cardiovascular disease and other NCD-related conditions, validating the evidence derived from previous cross-sectional and longitudinal observational studies.

\section{Central Chile: Mediterranean-like ecosystem and food production}

The Mediterranean Basin is the largest Mediterranean ecosystem in the world. However, there are four more places in the world where Mediterranean ecosystems can be found: 
California, South Africa, Southwest Australia, and Central Chile (Figure 1). Geographically, these Mediterranean ecosystems are localized on the western coasts of continental landmasses, at latitudes comprised between 30 and $45^{\circ}$ north or south [37]. All of these regions are considered biodiversity hot spots with some of the world's best environments for agriculture and human habitation.

Cool, wet winters and hot, dry summers characterize the climate in these regions, and the vegetation is primarily evergreen or deciduous shrublands. Mediterranean agriculture is also defined by the cultivation of specific fruits, vegetables, and grains such as olives, grapes, garlic, lemons, oranges, tomatoes, chickpeas, eggplants, peppers, and fennel. In fact, the distribution of the primary olive oil and wine-producing regions of the world, two emblematic products from Mediterranean agriculture, is remarkably similar to that of the Mediterranean ecosystems. These ecosystems also determine livestock use, which includes mostly sheep and goats, leading to high availability of cheese and yogurt but low access to red meat and butter. These foods, together with fish and seafood harvested from Mediterranean coastal regions, are crucial components of MedDiets as indicated above.

The MedDiet is also a consequence of the global exchange of domesticated animal and plant species and gastronomic traditions of the Mediterranean region. Inhabitants of the Mediterranean regions devised culinary practices that rendered their cuisine attractive, healthy, and culturally important. However, the Mediterranean food basket is in fact the result of domesticated food species exchanged mainly between the Americas, Europe, North Africa, and Asia. Some

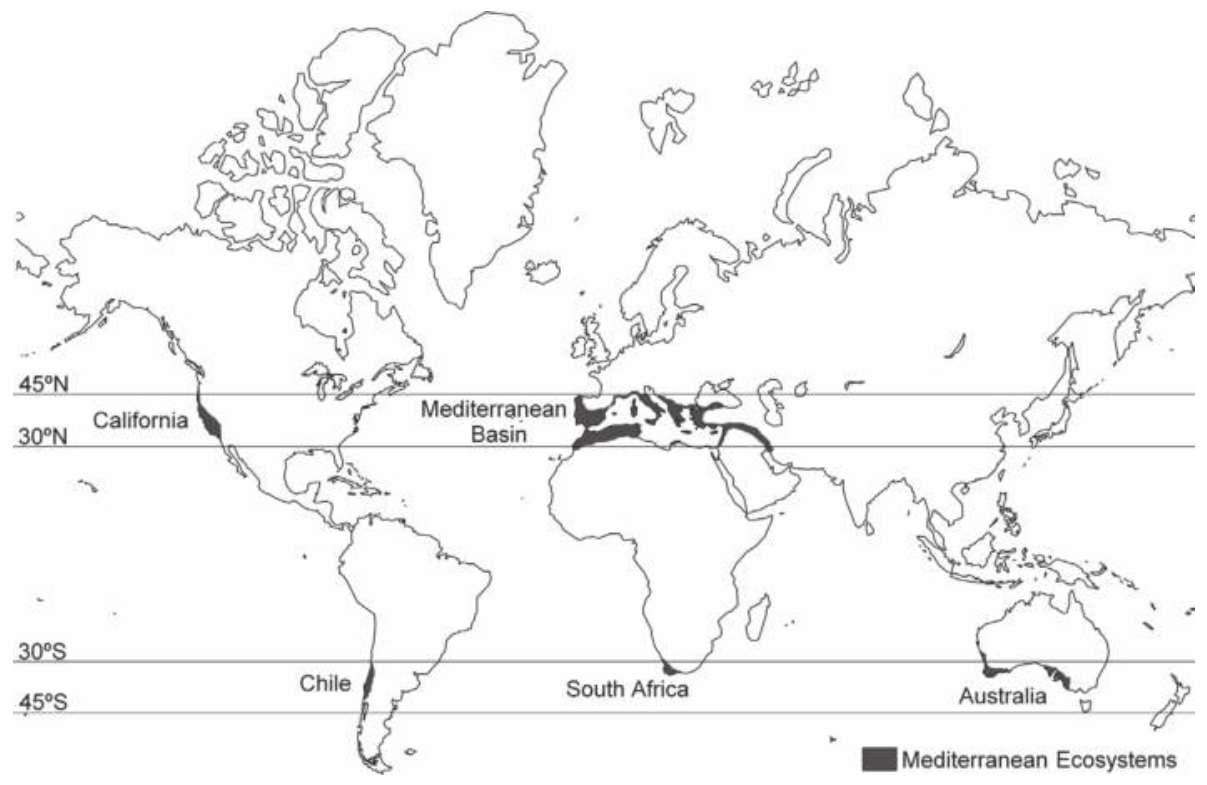

Figure 1. Mediterranean ecosystems of the world. There are five main Mediterranean ecosystems located between latitudes 30 and $45^{\circ}$ of both hemispheres [50]. 
emblematic foods are native to the Americas, such as potatoes and tomatoes, which are from the Andean regions of Ecuador, Peru, and Chile. Common beans and green beans along with sweet and hot peppers are native to Mexico, Central America, Bolivia, and Peru. Corn is native to Mexico and the northern zone of Central America, broad beans and artichokes come from North Africa, chicken and rice come from China, and citrus comes from Southeast Asia, while garlic and onions are native to Central Asia. Meanwhile, eggplants come from India, and many spices come from Asia and other regions (Figure 2) [38].

Central Chile, a $1000 \mathrm{~km}$ narrow band (30-36 ${ }^{\circ}$ ) located west of the Andes mountains, also exhibits a Mediterranean-like environment, as previously reviewed in Ref. [39]. The ecological conditions of Central Chilean result in agricultural and livestock patterns similar to those generated in countries located in the Mediterranean Basin. In fact, data from the UN Food and Agriculture Organization indicated that Chilean food production, availability, and consumption at the end of the twentieth century were similar to that which was reported in Italy and Spain [40].

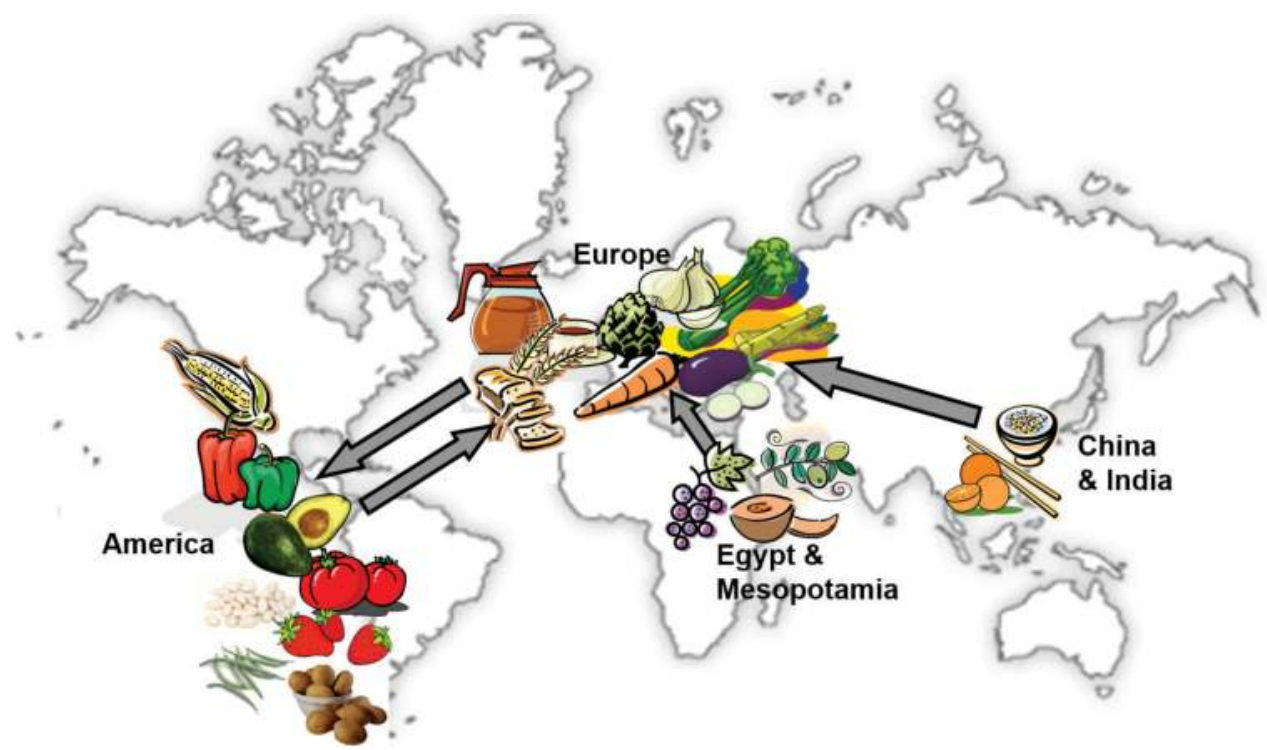

Figure 2. The Mediterranean diet includes foodstuffs derived from animal and plant species that originated in different regions of the world.

\section{Mediterranean diet style in Chile}

Traditional Chilean cuisine uses ingredients and cooking techniques that are very similar to those utilized in the Mediterranean culinary traditions of Spain, Italy, and Greece [37, 40]. Characteristic Chilean dishes, such as charquicán (stewed vegetables with minced meat), porotos 
granados (stewed vegetables, basil, and fresh beans), porotos con riendas (stewed vegetables, beans, and pasta), cazuela de ave (boiled chicken, potatoes, pumpkin pieces, green beans, carrots, parsley, rice, and corn), and tomaticán (stewed onion, tomato, corn, and minced meat), are prepared on a flavored base that contains onions, oregano, cumin, black pepper, paprika, and sautéed garlic. This flavor base is similar to Spanish sofrito, Italian soffritto, or French mirepoix. Fish (such as conger eel in caldillo de congrio) or seafood (such as mussels, scallops, sea squid, barnacles, and other shellfish in mariscal) are often prepared in Mediterranean-type soups made with tomatoes, carrots, potatoes, onions, red and green peppers, garlic, oregano, chili peppers, and parsley. Traditionally, Chilean dishes are also served with fresh parsley and cilantro. Two popular salads are prepared with tomato, onion, and parsley or celery combined with avocado and walnuts. Salads are usually dressed with oil, salt, and lemon juice. Traditional pebres are prepared using finely chopped onion, garlic, tomato, parsley, chili, and cilantro and are dressed with vinegar, salt, and oil (Figure 3). Wine consumption is also an important part of Chilean culture.

Traditional Chilean cuisine thus exhibits key Mediterranean characteristics, and the promotion of MedDiet in Chile offers a great opportunity for the management of ongoing epidemiological transition and increasing incidence of risk conditions and NCDs in Chile [37, 41]. In fact,

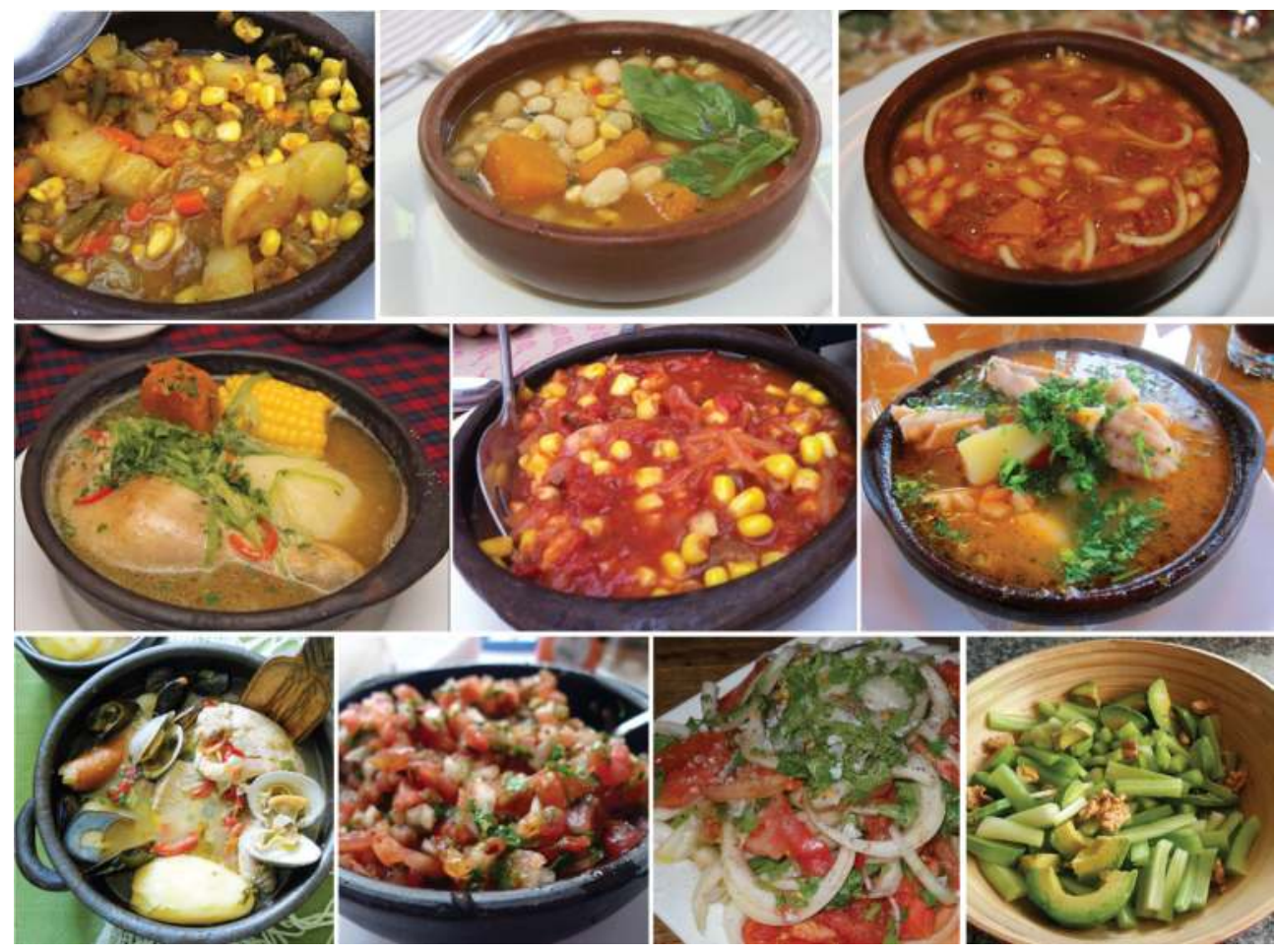

Figure 3. Traditional dishes from Chile. Chilean recipes use ingredients and cooking techniques that are very similar to those utilized in culinary traditions of the Mediterranean region. Upper row: charquicán, porotos granados, and porotos con riendas; middle row: cazuela de ave, tomaticán, and caldillo de congrio; lower row: mariscal, pebre, Chilean salad, and salad with celery, avocado, and nuts. 
data from 2010 to 2015 collected through Programa Aliméntate Sano (www.alimentatesano.cl), an open-access online platform created and led by our institution to provide general lifestyle (including the MedDiet) and health information and resources to the Chilean population, indicate that Chilean adults who exhibit higher adherence to MedDiet (based on a locally developed and validated score) [42] have a lower prevalence of overweight, obesity, and MS [43]. Furthermore, this cross-sectional study suggests that even small improvements in adherence to MedDiet may be associated with a significant decrease in obesity/overweight and MS, though this claim requires further testing.

In spite of the importance of MedDiet in Chile, current economical and epidemiological transitions as well as ongoing lifestyle changes are negatively impacting the use of traditional cuisine and dietary habits in the Chilean population [37, 40, 41]. Information obtained from the Programa Aliméntate Sano database ( $\mathrm{n}=53,366$ subjects) demonstrate that only $10 \%$ of the sampled population complies with a Mediterranean-type diet (2) with higher adherence in women, at older ages, and at higher educational levels. These latter demographic trends are comparable to those obtained with similar MedDiet indexes applied in other Mediterranean and non-Mediterranean populations.

\section{Dietary Mediterranization studies in Chile}

In Chile, some studies have already been conducted to evaluate the impact of the MedDiet on laboratory and clinical parameters.

In one study conducted in 1998, individuals subjected to a 3-month MedDiet intervention showed greater antioxidant capacity and less oxidative damage [44], better fatty acid profile [45], hemostasis [46], and endothelial function [47] compared with those following a Western diet. In a second more recent study (2014), a calorie-restricted MedDiet resulted in decreased serum levels of advanced glycation end products in premenopausal women with overweight or obesity [48].

Finally, dietary Mediterranization and its effect on the prevalence of MS and its components were evaluated at a workplace. During this intervention, a Mediterranization of the participants' diet was observed (measured by MedDiet score [42]) in association with a significant improvement of MS components as well as MS itself by the end of the study [49].

\section{Concluding remarks}

The MedDiet has been shown, with ample scientific solvency, through both observational and interventional studies, numerous benefits in the prevention, and treatment of high-risk conditions and/or NCDs; these benefits are most likely explained by the MedDiet's favorable composition including a wide variety of important bioactive compounds and nutrients.

With regard to our country and based on the ecosystem, agricultural conditions, and culinary traditions of Central Chile, the MedDiet may play a key role in public policies for health promotion and disease prevention. It also offers enormous expectations - beyond healthcare - for 
well-being improvement, economic and social development, and global quality of life advancement in the Chilean population and society.

\section{Acknowledgements}

We would like to acknowledge the leading role of the late Dr. Federico Leighton in promoting and studying the application of the Mediterranean diet in Chile. Research reported by our group in this article has been supported by grants from Fundación Alimenta and Fundación Banmédica (Chile).

\section{Author details}

Guadalupe Echeverría ${ }^{1}$, Catalina Dussaillant ${ }^{1}$, Emma McGee ${ }^{1}$, Inés Urquiaga ${ }^{1}$, Nicolás Velasco ${ }^{2}$ and Attilio Rigotti ${ }^{1,2 *}$

*Address all correspondence to: arigotti@med.puc.cl

1 Center for Molecular Nutrition and Chronic Diseases, School of Medicine, Pontificia Universidad Católica de Chile, Santiago, Chile

2 Department of Nutrition, Diabetes and Metabolism, School of Medicine, Pontificia Universidad Católica de Chile, Santiago, Chile

\section{References}

[1] WHO. Attaining the Nine Global Noncommunicable Diseases Targets; A Shared Responsibility: Switzerland; 2014

[2] Willett WC, Stampfer MJ. Current evidence on healthy eating. Annual Review of Public Health. 2013;34:77-95

[3] Mozaffarian D, Appel LJ, Van Horn L. Components of a cardioprotective diet: New insights. Circulation. 2011;123(24):2870-2891

[4] Sofi F, Macchi C, Abbate R, Gensini GF, Casini A. Mediterranean diet and health. Biofactors. 2013;39(4):335-342

[5] Dussaillant C, Echeverria G, Urquiaga I, Velasco N, Rigotti A. Current evidence on health benefits of the mediterranean diet. Revista Médica de Chile. 2016;144(8):1044-1052

[6] Keys A. Coronary heart disease in seven countries. Circulation. 1970;41(4 Suppl):1-211

[7] Keys A. Mediterranean diet and public health: Personal reflections. American Journal of Clinical Nutrition. 1995;61(6 Suppl):1321S-1323S 
[8] Urquiaga I, Echeverría G, Dussaillant C, Rigotti A. [Origin, components and mechanisms of action of the Mediterranean diet]. Revista Médica de Chile. 2017; 145(1):85-95.

[9] Simopoulos AP. The Mediterranean diets: What is so special about the diet of Greece? The scientific evidence. Journal of Nutrition. 2001;131(11 Suppl):3065S-3073S

[10] Saura-Calixto F, Goni I. Definition of the Mediterranean diet based on bioactive compounds. Critical Reviews in Food Science and Nutrition. 2009;49(2):145-152

[11] Bullo M, Casas R, Portillo MP, Basora J, Estruch R, Garcia-Arellano A, et al. Dietary glycemic index/load and peripheral adipokines and inflammatory markers in elderly subjects at high cardiovascular risk. Nutrition, Metabolism, and Cardiovascular Diseases. 2013;23(5):443-450

[12] Konstantinidou V, Covas MI, Sola R, Fito M. Up-to date knowledge on the in vivo transcriptomic effect of the Mediterranean diet in humans. Molecular Nutrition \& Food Research. 2013;57(5):772-783

[13] Schwingshackl L, Hoffmann G. Mediterranean dietary pattern, inflammation and endothelial function: A systematic review and meta-analysis of intervention trials. Nutrition, Metabolism, and Cardiovascular Diseases. 2014;24(9):929-939

[14] Damasceno NR, Sala-Vila A, Cofan M, Perez-Heras AM, Fito M, Ruiz-Gutierrez V, et al. Mediterranean diet supplemented with nuts reduces waist circumference and shifts lipoprotein subfractions to a less atherogenic pattern in subjects at high cardiovascular risk. Atherosclerosis. 2013;230(2):347-353

[15] Estruch R, Martinez-Gonzalez MA, Corella D, Salas-Salvado J, Ruiz-Gutierrez V, Covas MI, et al. Effects of a Mediterranean-style diet on cardiovascular risk factors: A randomized trial. Annals of Internal Medicine. 2006;145(1):1-11

[16] Fito M, Guxens M, Corella D, Saez G, Estruch R, de la Torre R, et al. Effect of a traditional Mediterranean diet on lipoprotein oxidation: A randomized controlled trial. Archives of Internal Medicine. 2007;167(11):1195-1203

[17] UNESCO. Representative Lists of the Intangible Cultural Heritage of Humanity; 2010 [cited April 2011]. Available from: http://www.unesco.org/culture/ich/en/RL/00394

[18] Kastorini CM, Milionis HJ, Esposito K, Giugliano D, Goudevenos JA, Panagiotakos DB. The effect of Mediterranean diet on metabolic syndrome and its components: A meta-analysis of 50 studies and 534,906 individuals. Journal of the American College of Cardiology. 2011;57(11):1299-1313

[19] Martinez-Gonzalez MA, de la Fuente-Arrillaga C, Nunez-Cordoba JM, Basterra-Gortari FJ, Beunza JJ, Vazquez Z, et al. Adherence to Mediterranean diet and risk of developing diabetes: Prospective cohort study. British Medical Journal. 2008;336(7657):1348-1351

[20] Esposito K, Maiorino MI, Di Palo C, Giugliano D, Campanian Postprandial Hyperglycemia Study G. Adherence to a Mediterranean diet and glycaemic control in type 2 diabetes mellitus. Diabetic Medicine. 2009;26(9):900-907 
[21] Bonaccio M, Di Castelnuovo A, Costanzo S, Persichillo M, De Curtis A, Donati MB, et al. Adherence to the traditional Mediterranean diet and mortality in subjects with diabetes. Prospective results from the MOLI-SANI study. European Journal of Preventive Cardiology. 2016; 23(4):400-7

[22] Sofi F, Abbate R, Gensini GF, Casini A. Accruing evidence on benefits of adherence to the Mediterranean diet on health: An updated systematic review and meta-analysis. American Journal of Clinical Nutrition. 2010;92(5):1189-1196

[23] Sofi F, Macchi C, Abbate R, Gensini GF, Casini A. Mediterranean diet and health status: An updated meta-analysis and a proposal for a literature-based adherence score. Public Health Nutrition. 2014;17(12):2769-2782

[24] Sofi F, Cesari F, Abbate R, Gensini GF, Casini A. Adherence to Mediterranean diet and health status: Meta-analysis. British Medical Journal. 2008;337:a1344

[25] Trichopoulou A, Lagiou P, Kuper H, Trichopoulos D. Cancer and Mediterranean dietary traditions. Cancer Epidemiology, Biomarkers and Prevention. 2000;9(9):869-873

[26] Sofi F, Macchi C, Casini A. Mediterranean diet and minimizing neurodegeneration. Current Nutrition Reports. 2013;2:75-80

[27] Serra-Majem L, Roman B, Estruch R. Scientific evidence of interventions using the Mediterranean diet: A systematic review. Nutrition Reviews. 2006;64(2 Pt 2):S27-S47

[28] Martinez-Gonzalez MA, Salas-Salvado J, Estruch R, Corella DD, Fito M, Ros E, et al. Benefits of the Mediterranean Diet: Insights from the PREDIMED Study. Progress in Cardiovascular Diseases. 2015; 58(1):50-60

[29] de Lorgeril M, Renaud S, Mamelle N, Salen P, Martin JL, Monjaud I, et al. Mediterranean alpha-linolenic acid-rich diet in secondary prevention of coronary heart disease. Lancet. 1994;343(8911):1454-1459

[30] de Lorgeril M, Salen P, Martin JL, Monjaud I, Delaye J, Mamelle N. Mediterranean diet, traditional risk factors, and the rate of cardiovascular complications after myocardial infarction: Final report of the Lyon Diet Heart Study. Circulation. 1999;99(6):779-785

[31] Salas-Salvado J, Fernandez-Ballart J, Ros E, Martinez-Gonzalez MA, Fito M, Estruch R, et al. Effect of a Mediterranean diet supplemented with nuts on metabolic syndrome status: One-year results of the PREDIMED randomized trial. Archives of Internal Medicine. 2008;168(22):2449-2458

[32] Babio N, Toledo E, Estruch R, Ros E, Martinez-Gonzalez MA, Castaner O, et al. Mediterranean diets and metabolic syndrome status in the PREDIMED randomized trial. Canadian Medical Association Journal. 2014;186(17):E649-E657

[33] Estruch R, Ros E, Salas-Salvado J, Covas MI, Corella D, Aros F, et al. Primary prevention of cardiovascular disease with a Mediterranean diet. New England Journal of Medicine. 2013;368(14):1279-1290 
[34] Salas-Salvado J, Bullo M, Babio N, Martinez-Gonzalez MA, Ibarrola-Jurado N, Basora J, et al. Reduction in the incidence of type 2 diabetes with the Mediterranean diet: Results of the PREDIMED-Reus nutrition intervention randomized trial. Diabetes Care. 2011;34(1):14-19

[35] Valls-Pedret C, Sala-Vila A, Serra-Mir M, Corella D, de la Torre R, Martinez-Gonzalez MA, et al. Mediterranean diet and age-related cognitive decline: A randomized clinical trial. Journal of the American Medical Association Internal Medicine. 2015;175(7):1094-1103

[36] Toledo E, Salas-Salvado J, Donat-Vargas C, Buil-Cosiales P, Estruch R, Ros E, et al. Mediterranean diet and invasive breast cancer risk among women at high cardiovascular risk in the PREDIMED trial: A randomized clinical trial. Journal of the American Medical Association Internal Medicine. 2015;175(11):1752-60

[37] Urquiaga I, Echeverria G, Polic G, Castillo O, Liberona Y, Rozowski J, et al. Mediterranean food and diets, global resource for the control of metabolic syndrome and chronic diseases. World Review of Nutrition and Dietetics. 2008;98:150-173

[38] Leighton F, Urquiaga, I. The Mediterranean diets: Nutrition and gastronomy. In: Smith J, Charter E, editors. Functional Food Product and Development. Canada: WileyBlackwell; 2010. pp. 322-343

[39] Armesto JJ, Arroyo MTK, Hinojosa, LF. The Mediterranean Environment of Central Chile. New York: Oxford University Press; 2007

[40] Rozowski J, Castillo O. Is the Chilean diet a Mediterranean-type diet? Biological Research. 2004;37(2):313-319

[41] Albala C, Vio F, Kain J, Uauy R. Nutrition transition in Latin America: The case of Chile. Nutrition Reviews. 2001;59(6):170-176

[42] Echeverría G, Urquiaga I, Concha MJ, Dussaillant C, Villarroel L, Velasco N, et al. [Validation of self-applicable questionnaire for a mediterranean dietary index in Chile]. Revista Médica de Chile. 2016 Dec;144(12):1531-1543

[43] Echeverría G, McGee E, Urquiaga I, Jimenez P, D'Acuña S, Villarroel L, et al. Inverse associations between a locally validated Mediterranean Diet Index, Obesity/Overweight, and Metabolic Syndrome: Findings from a self-selecting sample of Chilean adults. Manuscript in preparation. 2017

[44] Urquiaga I, Strobel P, Perez D, Martinez C, Cuevas A, Castillo O, et al. Mediterranean diet and red wine protect against oxidative damage in young volunteers. Atherosclerosis. 2010;211(2):694-699

[45] Urquiaga I, Guasch V, Marshall G, San Martin A, Castillo O, Rozowski J, et al. Effect of Mediterranean and Occidental diets, and red wine, on plasma fatty acids in humans. An intervention study. Biological Research. 2004;37(2):253-261

[46] Mezzano D, Leighton F, Martinez C, Marshall G, Cuevas A, Castillo O, et al. Complementary effects of Mediterranean diet and moderate red wine intake on haemostatic cardiovascular risk factors. European Journal of Clinical Nutrition. 2001;55(6): 444-451 
[47] Leighton F, Cuevas A, Guasch V, Perez DD, Strobel P, San Martin A, et al. Plasma polyphenols and antioxidants, oxidative DNA damage and endothelial function in a diet and wine intervention study in humans. Drugs under Experimental and Clinical Research. 1999;25(2-3):133-141

[48] Rodriguez JM, Leiva Balich L, Concha MJ, Mizon C, Bunout Barnett D, Barrera Acevedo $\mathrm{G}$, et al. Reduction of serum advanced glycation end-products with a low calorie Mediterranean diet. Nutrición Hospitalaria. 2015;31(6):2511-2517

[49] Leighton F, Polic G, Strobel P, Perez D, Martinez C, Vasquez L, et al. Health impact of Mediterranean diets in food at work. Public Health Nutrition. 2009;12(9A):1635-1643

[50] Köppen V. Das geographische system der klimate. Köppen V, Geiger R, editors. Berlin: Gebrüder Borntraeger; 1936 